\title{
PREDICTIVE VALUE OF THE ANKLE-BRACHIAL INDEX IN THE EVALUATION OF INTERMITTENT CLAUDICATION
}

\author{
Nelson Wolosker, Ruben A Rosoky, Lívio Nakano, Márcio Basyches and \\ Pedro Puech-Leão
}

RHCFAP/3004

WOLOSKER N et al. - Predictive value of the ankle-brachial index in the evaluation of intermittent claudication. Rev. Hosp. Clín.

Fac. Med. S. Paulo 55(2):61-64, 2000.

SUMMARY: The purpose of this study was to determine whether the ankle-brachial index (ABI) could be used to predict the prognosis for a patient with intermittent claudication (IC).

We studied 611 patients prospectively during 28 months of follow-up. We analyzed the predictive power of using various levels of $\mathrm{ABI}-0.30$ to 0.70 at 0.05 increments — in terms of the measure's specificity (association with a favorable outcome after exercise rehabilitation therapy) and sensitivity (association with a poor outcome after exercise rehabilitation therapy). We found that using an $\mathrm{ABI}$ of 0.30 as a cut-off value produced the lowest margin of error overall, but the predictive power was still low with respect to identifying the patients with a poor prognosis after non-aggressive therapeutic treatment. Further study is needed to perhaps identify a second factor that could increase the sensitivity of the test.

DESCRIPTORS: Intermittent claudication. Risk factors. Diagnostic. Atherosclerosis. Complications.

Intermittent claudication (IC) is an early clinical manifestation of peripheral arterial occlusive disease (PAOD). Its evolution is relatively mild, with improvement in the majority of patients, permitting longer walking tolerance. Therefore, early clinical treatment is important $t^{1,2}$.

However, a significant number of patients with IC do not improve with noninvasive management or present a worsening of their vascular condition even with adequate management ${ }^{3}$, leading to a poorer quality of life or even to the risk of 1oosing the extremity.

Prior to clinical treatment it is desirable to know which factors could identify patients with a negative prognosis. In this way patients could benefit from early surgical or endovascular treatment, enhancing the quality of life and possibly changing the natural course of the disease.

The ankle-brachial index (ABI) permits an assessment of the level of hemodynamic changes of the lower limbs. Since the ankle blood pressure varies with the systemic blood pressure, we use this index to normalize the values, by dividing the ankle systolic blood pressure by the braquial systolic blood pressure.

This value has been used as a predictive factor. A variety of values have been suggested, but their validity has been questioned ${ }^{3,4}$.

From the Vascular Surgery Section, Department of Surgery, Hospital das Clínicas, Faculty of Medicine, University of Sao Paulo.
The objective of this study was to verify the value of the ABI, measured when starting treatment, to predict the prognosis of patients with intermittent claudication submitted to clinical treatment, with the 1owest margin of error.

\section{PATIENTS AND METHODS}

Five hundred and forty-three patients with IC of the lower limbs undergoing clinical treatment for a median time of 28.9 months were prospectively studied.

Upon admission, the ABI of all patients was recorded. Pressure in the upper limb was measured in the radial artery, and in both lower limbs in the dorsalis pedis and posterior tibial arteries. The highest value of systolic blood 
pressure of each leg (in dorsalis pedis artery or in posterior tibial artery) was divided by the highest value of the brachial systolic blood pressure (right or left arm).

The vascular outcome was determined by measuring the maximum walking distance using the progressive treadmill test ${ }^{5}$. Stabilization or increase of the distance walked with a tolerance of \pm 30 meters was considered favorable $(\mathrm{F})$.

The outcome of patients was coded in relation to the values of $\mathrm{ABI}$ arbitrarily set between 0.30 and 0.70 in 0.05 increments.

The margin of error was calculated for each ABI value established, taking into account their corresponding levels of sensitivity and specificity, using the formula:

$$
\text { error }_{1}+\operatorname{error}_{2}(\mathbf{1})
$$

where:

- error $_{1}=$ "false negative" - proportion of patients belonging to the category "improvement", whose ABI was lower than the adopted value;

- error $_{2}=$ "false positive" - proportion of patients belonging to the category "worsening", whose ABI was higher than the adopted value of ABI.

\section{RESULTS}

The results of the study are shown in tables 1-3.

Table 1 shows the outcome of patients on distance walking according to the iniital ABI values with various arbitrary cutoff values.

Table 2 shows the sensitivity and specificity levels for different values of ABI. We found that with lower ABI values, the sensitivity was higher and the specificity was lower.

Table 3 presents the values resulting from applying the formula 1 to each value of ABI. We observed that
Table 1 - Evolution of patients according to ABI.

\begin{tabular}{|c|c|c|c|c|c|}
\hline \multirow{3}{*}{ ABI } & \multicolumn{5}{|c|}{ Evolution } \\
\hline & \multicolumn{2}{|c|}{ Improvement } & \multicolumn{2}{|c|}{ worsening } & \multirow{2}{*}{$\begin{array}{l}\text { Total } \\
\mathbf{N}^{\mathbf{0}}\end{array}$} \\
\hline & $\mathbf{N}^{\mathbf{o}}$ & $\%$ & $\mathbf{N}^{\mathbf{0}}$ & $\%$ & \\
\hline$<0.30$ & 38 & 52 & 34 & 48 & 72 \\
\hline$>0.30$ & 357 & 75 & 114 & 25 & 471 \\
\hline$<0.35$ & 72 & 63 & 42 & 37 & 114 \\
\hline$>0.35$ & 323 & 75 & 106 & 25 & 429 \\
\hline$<0.40$ & 111 & 67 & 53 & 33 & 164 \\
\hline$>0.40$ & 284 & 75 & 95 & 25 & 379 \\
\hline$<0.45$ & 153 & 70 & 64 & 30 & 217 \\
\hline$>0.45$ & 242 & 74 & 84 & 26 & 326 \\
\hline$<0.50$ & 213 & 72 & 83 & 28 & 296 \\
\hline$>0.50$ & 182 & 74 & 65 & 26 & 247 \\
\hline$<0.60$ & 284 & 73 & 107 & 27 & 391 \\
\hline$>0.60$ & 111 & 73 & 41 & 27 & 152 \\
\hline$<0.70$ & 333 & 73 & 121 & 27 & 454 \\
\hline$>0.70$ & 62 & 69 & 27 & 31 & 89 \\
\hline
\end{tabular}

ABI - Ankle-brachial Index: Ankle systolic blood pressure of the affected limb divided by brachial systolic blood pressure.

Table 2 - Levels of sensitivity and specificity for different ABI values.

\begin{tabular}{ccc}
\hline ABI & Specificity & Sensitivity \\
\hline 0.30 & 0.23 & 0.90 \\
0.35 & 0.28 & 0.82 \\
0.40 & 0.36 & 0.72 \\
0.45 & 0.43 & 0.61 \\
0.50 & 0.56 & 0.46 \\
0.60 & 0.72 & 0.28 \\
0.70 & 0.82 & 0.16 \\
\hline
\end{tabular}

ABI - Ankle-brachial Index.

Table 3 - Margins of error for the different ABI .

\begin{tabular}{cccc}
\hline ABI & error1 & error2 & Error1+ error2 \\
\hline 0.30 & 0.089 & 0.797 & $\mathbf{0 . 8 8 6}$ \\
0.35 & 0.173 & 0.729 & 0.902 \\
0.40 & 0.268 & 0.643 & 0.910 \\
0.45 & 0.372 & 0.556 & 0.928 \\
0.50 & 0.530 & 0.430 & 0.960 \\
0.60 & 0.717 & 0.275 & 0.993 \\
0.70 & 0.854 & 0.193 & 1.047 \\
\hline
\end{tabular}

ABI - Ankle-brachial Index

Error 1 - False negative: Patients with improvement with ABI below the cut-off value. Error 2 - False positive: Patients with worsening with ABI above the cut-off value. the ABI cutoff value of 0.30 had the smallest margins of error.

\section{DISCUSSION}

$\mathrm{ABI}$ is a simple measure permitting the assessment of the rate of hemodynamic change in the lower limbs by comparing the pressures found in the distal arteries of the leg with the systemic pressure, normally measured in the arm.

Most patients managed for IC improve their walking tolerance; nevertheless, for a significant number (about $30 \%$ ), their condition either stabilizes or worsens. A poor prognosis has a wide range of consequences, but as a rule brings about a decreased quality of life ${ }^{6}$, in addition to leading to significant socioeconomic problems.

The minimum time required for achieving satisfactory results with exercise rehabilitation therapy is about three to six months $s^{3,7,8,9,10}$. In cases of a poor prognosis, the opportunity for a less invasive treatment may be lost because of the occlusion of an arterial stenosis $^{2,11}$ or progression of the preexisting thrombosis. In these cases, early surgical treatment may prove more efficient ${ }^{12}$ and avoid later revascularizations that will certainly be more extensive.

Passage of time may also cause loss of a surgical opportunity because of deterioration of the clinical condition and increase in the surgical risk ${ }^{13,14}$.

The predictive factors could be used to identify patients who would not have a positive outcome with noninvasive treatment and to alert physicians to the need for a surgical therapy (conventional or endovascular surgery) at an early stage.

In the literature, the ABI has been mentioned as a predictor of the vascular evolution and also of the clinical progress in patients with IC; however, its predictive power is controversial. 
The validity of this indicator is questionable $\mathrm{e}^{3,4}$, and with regard to the most adequate cut-off value for ABI, uncertainty exists concerning the value below which exercise rehabilitation therapy would likely be ineffective ${ }^{12,15,16,17}$.

All works undertaken until now are based upon the analysis of a pre-established pressure indicator coupled to the course of IC. In our study, we sought to relate the progress of the IC in terms of walking distance with different levels of ABI, using the analysis of the sensitivity and specificity to find the best cutoff value for ABI. The objective is to find the ABI value that differentiates between the cases whose course would be favorable (sensitivity) and those of poor prognosis (specificity). The best ABI value would be the one with the smallest margin of error for sensitivity and specificity combined.
Low values of ABI, found at the onset of treatment permit a high sensitivity and a. very low specificity. The converse was also observed (Table 2). The predictive value of this indicator, in such cases, becomes questionable. We then observed that to consider a change as significant, two measures of ABI must vary by at lease $14 \%{ }^{18}$. This was not encountered in our study.

By assessing the margin of error (formula 1), it was possible to undertake the joint analysis described above, matching the different results of the arbitrarily established ABI values. We observed that the ABI value with the lowest margin of error was 0.30 . However, although this value resulted in a high sensitivity $(90 \%)$, it also resulted in a very low specificity (23\%).

The inability to reliably and prospectively identify patients who would have a poor prognosis following exer- cise rehabilitation therapy using $\mathrm{ABI}$ scores of any level calls into question the predictive value of ABI. Although some researchers have reported a significant correlation of ABI with the course of vascular disease, they considered the practical value of the $\mathrm{ABE}$ as a predictive test to be limited ${ }^{17,19}$ or absent $^{3,4}$.

We conclude that the ABI value with the smallest margin of error for predicting the vascular progress of IC of the lower limbs is 0.30 . However, because of its low specificity, its predictive power for identifying patients who would not benefit from exercise rehabilitation therapy is weak, rendering its use in isolation insufficient for the outlining of the IC treatment protocol. Perhaps the association of ABI to other variables will prove to be more predictive.
WOLOSKER N e col. - Valor preditivo do índice tornozelo-braço na evolução de pacientes com claudicação intermitente. Rev. Hosp. Clín. Fac. Med. S. Paulo 55(2):61-64, 2000.

O objetivo deste estudo foi determinar a evolução da distância de marcha de pacientes com claudicação intermitente relacionando com o índice tornozelo-braço (ITB) e o valor deste índice como fator preditivo para o prog- nóstico desses pacientes.

Observou-se prospectivamente a evolução de 611 pacientes durante 28 meses. Analisamos o valor preditivo do ITB inicial usando vários valores de corte -0.30 a 0.70 em incrementos de 0.05 - em relação à especificidade (associação com uma evolução favorável após tratamento clínico) e sensibilidade (associação com uma evolução desfavorável após tratamento clínico). Encontramos o ITB de 0.30 como o valor de corte produzindo a menor margem de erro, mas seu valor preditivo ainda foi baixo para identificar os pacientes com mau prognóstico para o tratamento não invasivo. Estudos adicionais são necessários para se identificar um fator adicional que possa aumentar a sensibilidade do teste.

DESCRITORES: Fatores de risco. Claudicação intermitente. Diagnóstico. Aterosclerose. Complicações. 


\section{REFERENCES}

1. IMPARATO AM, KIM GE, DAVIDSON T et al. - Intermittent claudication: its natural course. Surgery 1975;78(6):795-799.

2. WALSH DB, GILBERTSON JJ, ZWOLAK RM et al. - The natural history of superficial femoral artery stenoses. J Vasc Surg 1991; 14(3):299-304.

3. O'RIORDAIN DS \& O'DONNELL JA - Realistic expectations for the patient with intermittent claudication. Br J Surg 1991;78(7):861-863.

4. GARDNER AW \& POEHLMAN ET - Exercise rehabilitation programs for the treatment of claudication pain. A meta-analysis. JAMA 1995;274(12):975-80.

5. GARDNER AW, SKINNER JS, CANTWELL BW et al. - Progressive vs single-stage treadmill tests for evaluation of claudication. Med Sci Sports Exerc 1991;23(4):402-8.

6. LAMMI U, KIVELA SL, NISSINEN A et al. - Predictors of disability in eldery Finnish men - a longitudinal study. J Clin Epidemiol 1989;42(12):1215-1225.

7. EKROTH R, DAHLOFF AG, GUNDEVALL B et al. - Physical training of patients with intermittent claudication: indications, methods, and results. Surgery 1978;84(5):640-643.

8. JONASON T, JONZON B, RINGQVIST I et al. - Effect of physical training on different categories of patients with intermittent claudication. Acta Med Scand 1979;206(4):253-258.

9. MANNARINO E, PASQUALINI L, MENNA M et al. - Effects of physical training on peripheral vascular disease: a controlled study. Angiology 1989;40(1):5-10.

10. ERNST E \& FIALKA V - A review of the clinical effectiveness of exercise therapy for intermittent claudication. Arch Intern Med 1993;153(20):2357-2360.
11. WHYMAN MR, RUCKLEY CV \& FOWKES FG. - A prospective study of the natural history of femoropopliteal artery stenosis using duplex ultrasound. Eur J Vasc Surg 1993;7(4):444-447.

12. WILSON SE, SCHWARTZ I, WILLIAMS RA et al. - Occlusion of supeficial femoral artery. What happens without operation. Am J Surg 1980;140(1):112-118.

13. NUNN DB - Symptomatic peripheral arteriosclerosis of patients under age 40. Am Surg 1973;39(4):224-228.

14. VALENTINE RJ, MACGILLIVRAY DC, DENOBILE JW et al. Intermittent claudication caused by atherosclerosis in patients aged forty years and younger. Surgery 1990;107(5):560-565.

15. JELNES R, GAARDSTING O, HOUGAARD JENSEN K et al. - Fate in intermittent claudication: outcome and risk factors. BMJ 1986;293(6555):1137-40.

16. DORMANDY JÁ \& MURRAY GD. - The fate of the claudicant - a prospective study of 1969 claudicants. Eur J Vasc Surg 1991;5(2):131-133.

17. NASCHITZ JE, AMBROSIO DA \& CHANG JB - Intermittent claudication: predictors and outcome. Angiology 1988;39(1 Pt 1):16-22.

18. JOHNSTON KW, HOSANG MY \& ANDREWS DF - Reproducibility of noninvasive measurements of the peripheral circulation. J Vasc Surg 1987;6(2):147-51.

19. JONASON T \& RINGQVIST I - Prediction of the effect of training on the walking tolerance in patients with intermittent claudication. Scand J Rehab Med 1987;19(2):47-50.

Received for publication on the $04 / 05 / 00$ 